\title{
The New Role of Instructors and Curators for the First-Year Architectural Design Students in Taiwan
}

\author{
Moon-Lin Jau' ${ }^{1}$, Naai-Jung Shih ${ }^{2}$ \\ ${ }^{1}$ Department of Interior Design, Hwa Hsia University of Technology, Taiwan \\ ${ }^{2}$ Department of Architecture, National Taiwan University of Science and Technology, Taiwan \\ Email: jmoonlin@ms28.hinet.net, shihnj@mail.ntust.edu.tw
}

How to cite this paper: Jau, M.-L., \& Shih, N.-J. (2017). The New Role of Instructors and Curators for the First-Year Architectural Design Students in Taiwan. Art and Design Review, 5, 44-51.

https://doi.org/10.4236/adr.2017.51004

Received: December 15, 2016

Accepted: January 14, 2017

Published: January 17, 2017

Copyright $\odot 2017$ by authors and Scientific Research Publishing Inc. This work is licensed under the Creative Commons Attribution International License (CC BY 4.0).

http://creativecommons.org/licenses/by/4.0/

(c) (i) Open Access

\begin{abstract}
Taiwan has become a renowned Chinese cultural showcase in recent years. For architectural instructors, bringing student class efforts to the public has become a part of pedagogical events and the purpose of this study. Instructors who are also designers have established a pattern of collaborating with local small galleries for organizing design exhibitions. The result is a new collaborate pedagogical pattern which enables design students to reach out to society and, in the meantime, open up a window of diversity for the galleries as test workshops for design practice. This pattern has been carried out for three years. The results not only encourage students, but also motivate them with an open-mind learning attitude in a real social space.
\end{abstract}

\section{Keywords}

Pedagogy, Cultural and Creative Space, Design Studio

\section{Introduction}

In recent years, numerous annual nationwide exhibitions have been held for academic design-related departments. One of the largest exhibitions in Taiwan, Young Designers' Exhibition or YODEX, has attracted 126 departments from 63 local universities and colleges, plus 16 design schools from 5 foreign countries. In total, more than 9000 students and 4000 works are displayed over a period of 4 days. The exhibition has also attracted more than 95,000 visitors in 4 days (Taiwan Design Center, 2016). For years, most of the showroom partitions were torn down immediately after the exhibition, without being recycled.

YODEX is usually held in May, close to the end of a semester. Students usually have to save money and prepare for a long time ahead of this event. The advan- 
tage is obvious, in which an international interaction platform has been created. While this exhibition may be very common for professional designers, it nevertheless is very time- and resource-consuming for students. In order to display as many works as possible, exhibitions are usually held at the end of a semester. Although works which illustrate a chronological learning trail are good, the workload at the end of a semester usually adds to students' burden and potentially compromises the quality of the exhibition. Although some visitors may understand the concepts and mockups developed during the design process, the exhibition focuses on the final results instead of the entire design process. In other words, many design development aspects are not introduced.

The biggest challenge of YODEX and other graduation exhibitions are the limited number and opportunity of exposure. For the rest of the three college years, very few exhibitions were held outside the university, so smaller scale exhibitions with more frequent occurrences may be a solution for this situation, especially for the first year or junior students still in school. This concern has led to an alternative strategy, holding an exhibition in the middle of a semester. The scale does not have to be large. With an appropriate arrangement of works and concept illustration, the learning process can also deliver design requirements and solutions to public.

The purpose of this study is to incorporate the pedagogical model of architectural design and the business model of an art gallery for the first-year architectural design studio, and form the viewpoint of instructor, also as a curator. In contrast to one large scale exhibition in four years or one exhibition each semester, an experiment of one exhibition in the middle of a semester or near the end has been tested for three years. The exhibition will act like a footprint of the learning process for students and instructors as well.

\section{Space as a Platform or a Showroom}

Art gallery tops the choice among different types of space being considered for mid-semester exhibition. The function of an art gallery can be classified into three parts: a showroom, a place to trade arts, and being the manager of artists. A showroom is a place that provokes interaction between people and arts. The interaction, which is a specific kind of local cultural experience, may lead to a new creation of arts (Artlib, 2013; Lin, 2015). As an incubator, the scale of a gallery has gradually changed into twofold: a large scale chain gallery and a small individual one (Tully, 2015). The latter, with limited resources and supports for young artists, has created new business patterns including an artist- or curator-oriented display, a combination of showroom and coffee shop or book store, or an education program (Chen, 2013). A clear message has been delivered that this is a gallery for everyone and is also a community art center with auxiliary functions like ticket sales or short art courses.

In addition to creating values for arts, artists, and collectors, the appropriate business model and elements have to be analyzed (Wang, 2012). The value of a gallery is based on all the possible values made by the creativity or the diversity 
of the arts it displayed. The value-added model of a gallery usually has to be adjusted dynamically by the strategy that can accommodate the changes of scales in these days (Wang, 2012).

The important viewpoint of the incubator for future artists with diversified interests should be extended to college students. Combination the function of a local gallery and the student works from the Department of Architecture has become the first step to achieve that. The collaboration not only creates a connection between the future designers and the clients, but also educates neighborhood community with better understanding of architectural design.

A space for exhibition is a platform for the exchange of creative design or to share design-related thoughts. To support the functionality of a platform, both software and hardware have to be integrated for ensuring efficient and effective communication. Software can cater to the exhibition program, design logistics, or social network. Hardware can be the facilities or environment to support the exhibition. Both software and hardware are run by the curator or the contributors of the platform.

There are situations where the emphasis is disoriented, i.e. the exhibitions are the hardware, instead of being run or supported by hardware. While designing a typical creative space for art display is common, cases nevertheless show that the space takes control over the exhibition. While the interior design should be as beautiful as an exhibition, the showroom is not the purpose itself. The term "creative space" is frequently used, even a restaurant can be one without typical exhibition activity. So, it remains to be seen if a restaurant is a dining space without an exhibition program, or a creative space with a well-established exhibition program with auxiliary support facilities like a coffee shop.

\section{When a Pedagogical Model Meets a Business Model}

The exchange of creative design needs a platform and an operations model. The public cultural and creative spaces (CACS) in Taiwan are usually promoted and sponsored by governments. The purpose is to encourage as many artistic subjects as possible, from music, dance and painting, to multimedia. It is similar to a creative platform for professionals or amateurs, and for practice or academics. There is also private CACS which is created based on a business model, combining promotion, preservation and profit. For a young artist, both the public and private CACSs have to go through a series of evaluations prior to the exhibition or investment, let alone student works. The pedagogy model of performance simulation, generation, evaluation (Oxman, 2008) is difficult to reach out beyond the campus. The result is usually a typical corridor linear panel-stage display layout in an empty hallway (Figure 1). Still, many design varieties exist (Figure 2) and design communication should be extended to an environment with more public exposure.

\section{Cultural and Creative Spaces (CACS)}

A CACS is not just a space; it needs a theme or a program to operate. A typical 


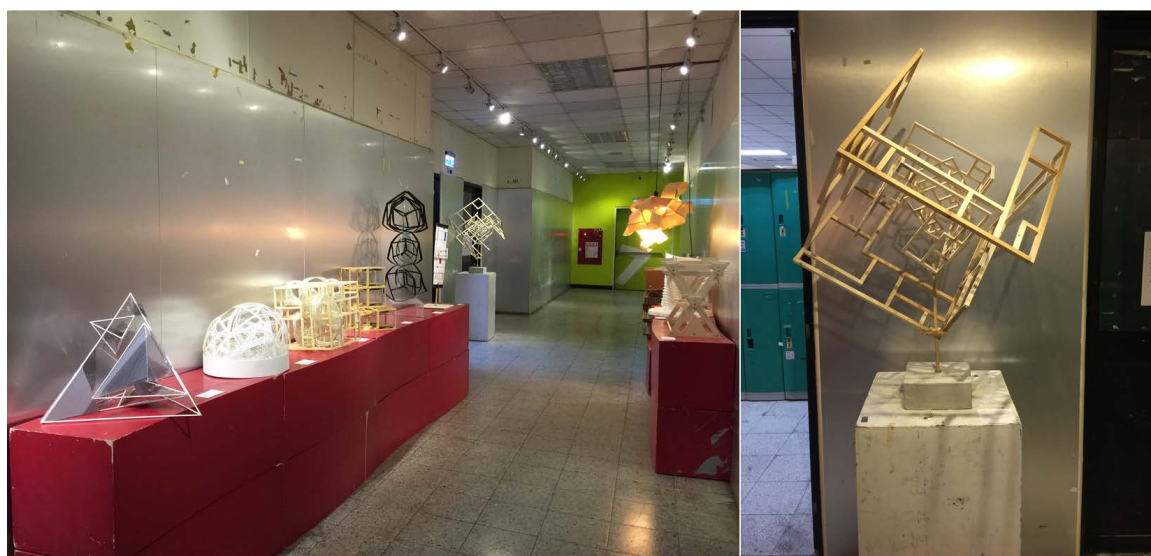

Figure 1. A typical linear panel-table display layout in a corridor outside a design studio.

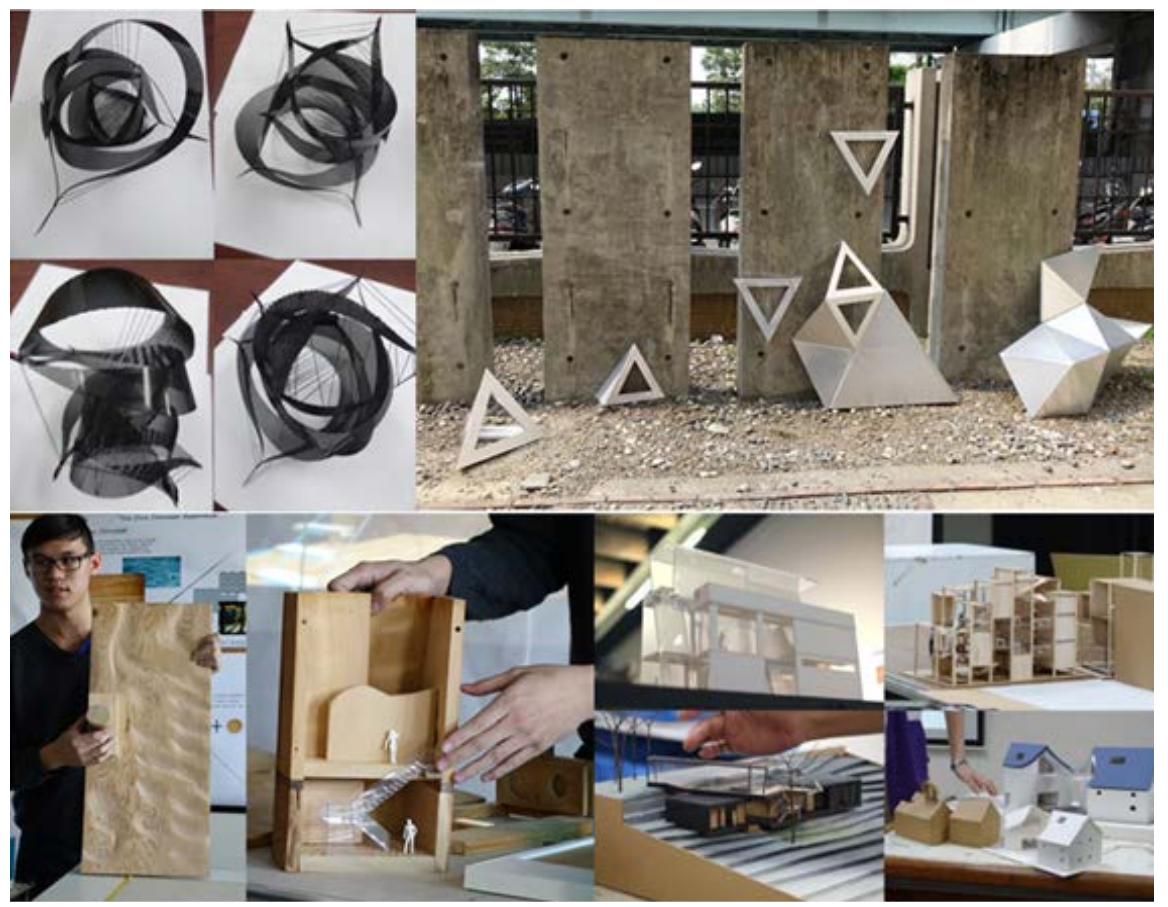

Figure 2. Design projects with a number of varieties.

solution, or the easiest approach, is to combine daily activities with pre-defined design subjects. An example can be found in local restaurants or tea houses (Youth Design ${ }^{3}$, 2015), which have created new food culture with modern or traditional design language. Related spaces or applications can be found in the following types:

- New constructions or new designs: restaurant (Wang \& Wang, 2015; Yao, 2015), tea house;

- Old buildings: distribution office of Taiwan Tobacco \& Liquor Corporation (Youth Design ${ }^{1}$, 2015), elementary school (Youth Design², 2015), train station warehouse, dormitory, residence, granary;

- Historical buildings: renovated into a CACS for phonograph, music box (NewsRadio, 2013). 


\section{The Pros/Cons of Using Coffee Shops for Exhibitions}

Exhibitions in CACS have been a standard combination for a long time. CACS as coffee shop seems to be a perfect alternative, since people can enjoy coffee and snacks, while casually enjoying visual contact with surrounding design works. A space with appropriate flexibility would benefit from combining both models (Figure 3). Based on the statistics of the Minister of the Economy, the top 5 coffee chains have added up to 593 shops, a 7.9\% increase from 2012 (Lin, 2013). In the ninth month of 2015, the number of coffee shops reached 2435, for a $12 \%$ yearly increase (Kuo, 2015). The shops with special cultural characteristics or being list as "must visit" are the top choice for exhibitions.

Nevertheless, in a coffee shop, the original different business model led to a different space layout; consequently, very limited table display space is available in a coffee shop. All of the table-based display has to be modified to make the best use of vertical wall or panels. One of the solutions is to create small horizontal spaces using laminates, shelves, or even acrylic boxes supported by an existing hanging system. With proper layout lighting fixtures, walls are face-lifted into a gallery-like display panels, except that more leisure atmosphere is offered (Figure 4).

\section{Reaching out to Society}

The original exhibitions were made by the first-year architectural students. The

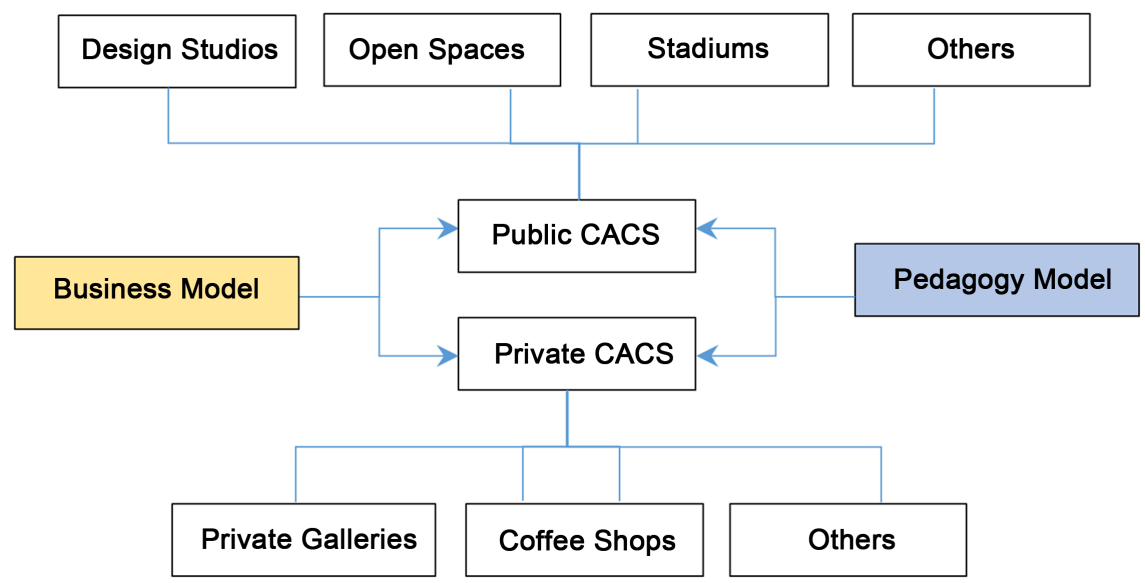

Figure 3. The inter-relationship between a business model and a pedagogical model.

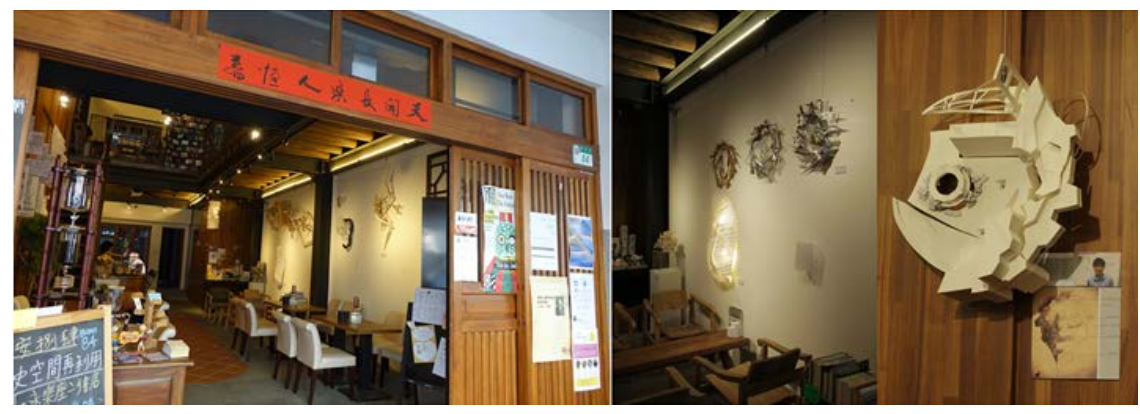

Figure 4. An integration of CACS, a coffee shop, and exhibition (top). 
purpose was to open the minds of students to public opinion, instead of being limited to the university. Public opinion, whether professional or amateur, helps students to re-think the ways their designs interact with people (Figure 5). Most likely this is the first exhibition in a student's life. Many students invite their family members to exhibitions, and that indirectly opens up the minds of parents, especially when a lot of adaption has to be conducted in the first year of university. Reaching out to society does not have to be on a large scale. A small community gallery (Figure 6) is also feasible and at a more accessible human scale.

\subsection{Connections}

Social media have created a prevailing manner of exhibition. Most early exhibitions were static, i.e. the designs only showed up in the gallery and all the people had to visit in person to see or to experience the works. These days, Facebook ${ }^{\oplus}$ (FB) allows users to stream activity in real time, and any person can put his/her design interpretation on YouTube $^{\oplus}$ and count the hit rate, let alone Instagram ${ }^{\circledR}$ or Twitter ${ }^{\oplus}$. Specific group like Pinterest ${ }^{\oplus}$ is more focused on the design-oriented interaction that can be shared by people who are familiar or who have not learned some topics.

It is possible that when a small gallery or one-person gallery was selected, very few responses were received. Other than the internet media, the exhibitions have discovered a specific traditional 2D media that has evolved with a new role: the tour book or magazine. Many foreign and local tourists (in the middle of Figure 7) plan their tours based on the sightseeing information of Taiwan. Although people can check similar information on the internet, the most recent activi-

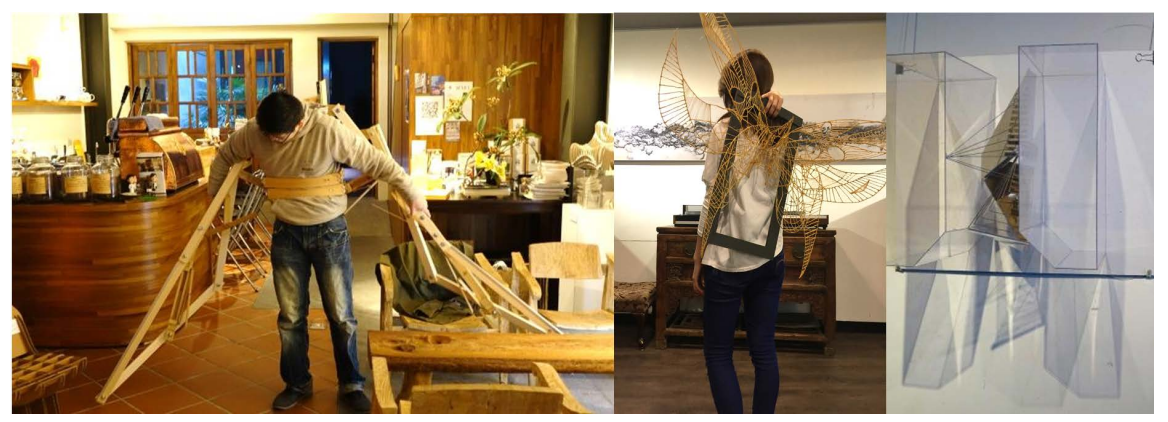

Figure 5. The in-shop design demonstration and modified display installation.

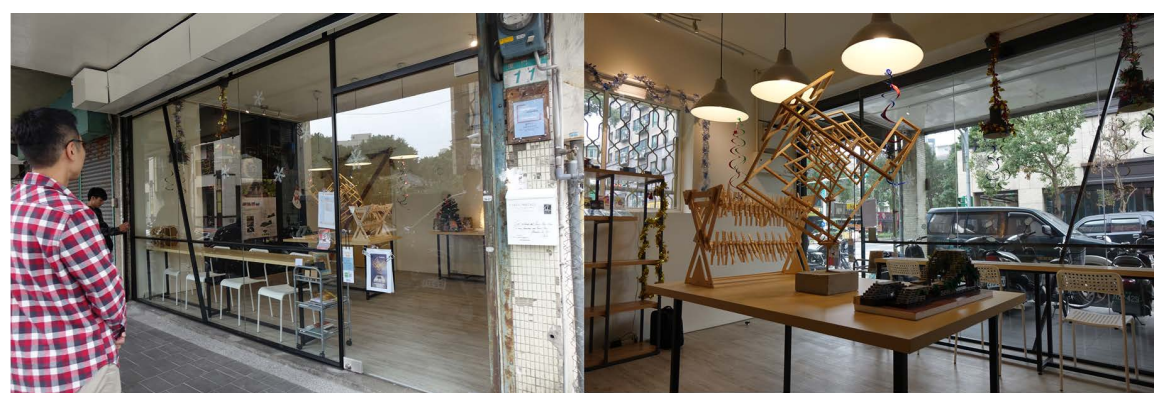

Figure 6. The connection of a small gallery and a community. 
ties are sometimes updated with more detailed introductions in the magazines published monthly (to the left of Figure 7). Tourists from different countries visited the gallery and left comments on the gallery's FB. Students are also happy to see their design shown in different types of media, which increases the credential of their portfolios.

\subsection{Activities: Forum, Seminars}

Other than pedagogy-oriented exhibitions, exhibitions for artists and designers are also held frequently in the same place. The exhibitions are usually held with forums or seminars in which the artists and designers can meet audiences faceto-face. Exhibitions are also open to children who can play/interact with the design directly (Figure 8). The activities of forum or seminars also inspire student's works that the interactions are now part of new design resources for the rest of their college years.

\section{Conclusion}

A new model that combines business and pedagogical characteristics has been created. The model applies public business space as a platform or a showroom to exchange creative design or to share design-related thoughts. The space is also considered as an incubator for future artists with diversified opportunities. The original motivation came from the new roles of architectural design instructors and curators in Taiwan. The combination of the two roles has proven to be very successful not only for the first-year students, but also for the family member's and public perception of the academic activities. In the future, new opportunities

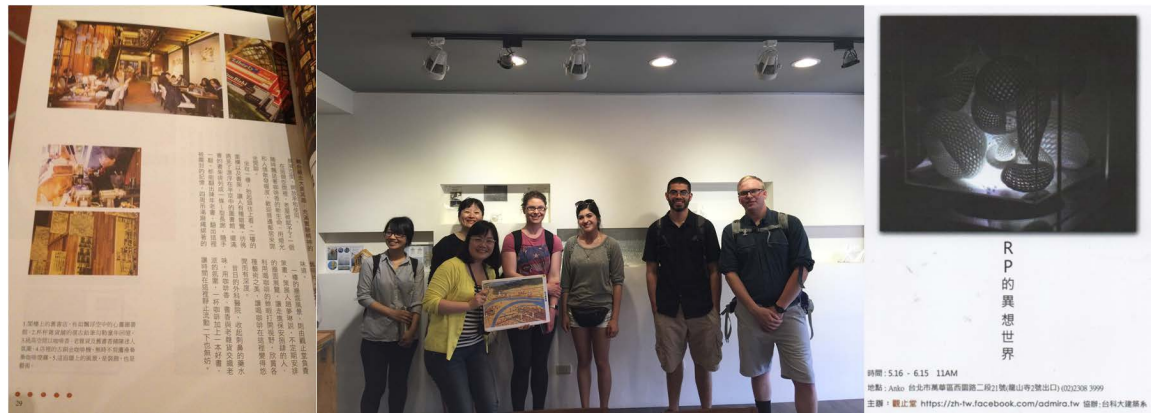

Figure 7. Report from monthly magazine (left), foreign visitors (middle), and poster (right).

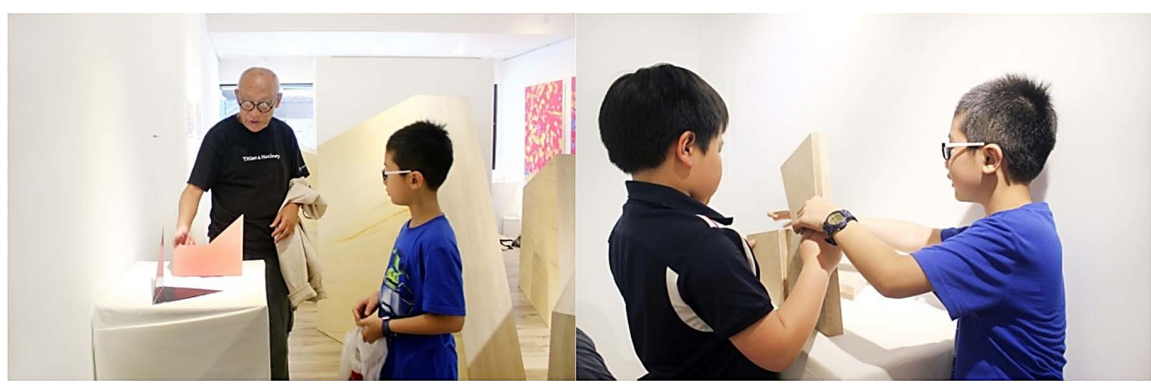

Figure 8. The interaction between children and artworks. 
will be created to have students and professional designers gather together with broader instructional opinions invited.

\section{References}

Artlib (2013). Gallery Industry Analysis and the Creative Management Pattern. International Cover, Global Chinese Art Net. http://artnews.artlib.net.tw/602/cover.html

Chen, S. H. (2013). Let's Stroll around Interesting Art Galleries in UK-Part 1. Global Chinese Art Net.

http://artnews.artlib.net.tw/37/352/\%E4\%BE\%86\%E9\%80\%9B\%E6\%9C\%89\%E8\%B6\% A3\%Е7\%9A\%84\%E8\%8B\%B1\%E5\%9C\%8B\%E8\%97\%9D\%E5\%BB\%8A\%EF\%BC\%88 \%Е4\%B8\%8A\%EF\%BC\%89.html

Kuo, H. H. (2015). The Rising Trend of Coffee Shops-The Return Ratio on Investment Reaches 2.6\% in FuJin Street, MinShan District. InforTimes, ChinaTimes. http://www.chinatimes.com/realtimenews/20151103003835-260410

Lin, C. N. (2013). 135 Shops in 6 Years - The Coffee Shop Chains in Great Business Opportunity. http://www.ettoday.net/news/20131205/304064.htm

Lin, I. S. (2015). Double Square Gallery-The Re-Imagination of Space. http://magazine.chinatimes.com/artco/20150625004704-300601

NewsRadio (2013). Transform Old Houses into Cultural and Creative Spaces-Stimulating the Creative Capability of Taipei. http://www.bcc.com.tw

Oxman, R. (2008). Digital Architecture as a Challenge for Design Pedagogy: Theory, Knowledge, Models and Medium. Design Studies, 29, 99-120. https://doi.org/10.1016/j.destud.2007.12.003

Taiwan Design Center (2016). Yodex. http://www.yodex.com.tw/visitors/yodex history

Tully, J. (2015). Can the Single-Venue Gallery Survive? Art+Auction, BlouinArtinfo.

Yao, S. (2015). The First Curatorial-Based Restaurant in Taiwan-The Taipeiing. http://www.chinatimes.com/realtimenews/20150813002034-260405

Youth Design $^{1}$ (2013). The Origin of Creativity-The ChungShanCreativity Base URS21. http://www.youthdesign.org.tw/link5-1 view.asp?id=39

Youth Design ${ }^{2}$ (2013). Dream Base of Art-BanChiao 543 Special District of Art. http://www.youthdesign.org.tw/link5-1 view.asp?id=50

Youth Design ${ }^{3}$ (2013). 7-3 Tea House-Tasting Tea and Tasting Creativity. http://www.youthdesign.org.tw/link5-1 view.asp?id=51

Wang, Y. Y. (2012). An Exploratory Study of Latest Business Model Innovation in Taiwan" Art Galleries. Master Thesis, National Dong Hwa University.

Wang, J. Y., \& Wang, I. H. (2015). All You See and All You Eat Are Art-The Cultural and Creative Restaurant of Taipeiing. http://www.chinatimes.com/realtimenews/20150813002074-260405 
Submit or recommend next manuscript to SCIRP and we will provide best service for you:

Accepting pre-submission inquiries through Email, Facebook, LinkedIn, Twitter, etc. A wide selection of journals (inclusive of 9 subjects, more than 200 journals)

Providing 24-hour high-quality service

User-friendly online submission system

Fair and swift peer-review system

Efficient typesetting and proofreading procedure

Display of the result of downloads and visits, as well as the number of cited articles Maximum dissemination of your research work

Submit your manuscript at: http://papersubmission.scirp.org/

Or contact adr@scirp.org 